to the different pathological changes, which are clinically recognized as the signs and symptoms of the disease.

Evidently, then, the length of time which will elapse before a certain sign is manifested, or during which it will remain (even its very occurrence or the severity of the change) must depend on many factors which may be most simply grouped and expressed as the relative "virulence" of the morbific element, and the "vitality" of the cells composing the individual attacked. On this account, then, we might expect that the periods above mentioned would show considerable differences in time of appearance and duration, and from our own experience and that of others we learn that such is the case; for, as T. v. Jürgensen ${ }^{1}$ in his excellent article forcibly remarks, "we know that living beings taking a contagion from other living beings are not governed-at least so far as we can ascertain - by inflexible rules, such as can be applied to the force and frequency of the blows of a steam hammer." Under these circumstances we can hardly refrain from asking ourselves whether there is any advantage in dividing a disease into definite stages, but a little experience soon assures us that the course of the majority of cases is remarkably constant, and the duration, etc., of the various stages of each disease becomes of the greatest assistance in making a differential diagnosis. As the writer I have quoted, however, says, we must "bear in mind that they represent the course of an average case, the accepted length of the stages marking the progressive development of an average infection." Deviations from the standard will often be noted, bat this does not necessarily imply that they are deviations from the " normal," since what we call " normal" only represents the average case.

It is, of course, distinctly unfortunate that in natura phenomena we are so frequently unable to fix a rule which will apply to all circumstances. We learn at first that scarlet fever say commences suddenly, the distinctive exanthem appearing in the subsequent 24 hours, and are then puzzled by occasionally meeting with a case in which its appearance is delayed two, three, or four days. Similarly with measles the teaching becomes engrafted in our minds that the onset occurs gradually, catarrhal symptoms being followed on the fourth day by a distinctive rash, which is first seen about the face. Subsequently we meet with cases in which the prodromata preceding the exanthem are longer or shorter than this period, or the rash makes its appearance in an unusual situation, and many of us immediately begin to question the correctness of our diagnosis. It is with the view of emphasizing these irregularities, as regards the early stages of measles, that I wish to refer to the following cases.

According to v. Jürgensen prodromata may be practically absent in an attack of measles, or constitutional symptoms may arise soon after infection occurs. As an example of the former occurrence I may mention a case reported by Dr. Julius Grober. ${ }^{2}$ The patient was a waiter, 16 years of age, who, with the exception of vaccination and "rheumatism of the joints," had been previously quite well and strong until the day before his admission to the hospital. $\mathrm{He}$ then complained of headache, and the same evening noticed small red spots on the left side of the forehead. Subsequently the rash spread over the nose, cheeks, breast, and back, and the following day was well marked, so that from its appearance; the associated temperature, and the catarrhal symptoms there could be no doubt that the illness was an attack of measles.

From a study of the literature, Dr. Grober states that he has only been able to find one similar case (recorded by Embden) in which the stage of invasion was practically absent. More common, however, are the instances in which the prodromal stage is unusually prolonged, the two following cases serving as examples :

CASE I-A boy, H. B., aged 9, was reported on the night of April 24th to have had a "croupy cough." The next day he seemed quite well, and there was no pyrexia. On April 26th, however, there was a thin serous discharge from the nares, the first alteration in the temperature $\left(99.4^{\circ} \mathrm{F}\right.$.) occurring on the evening of the $27 \mathrm{th}$. On each subsequent day the pyrexia became more marked, whilst on April 28th there was laryngeal cough with slight retraction. On May ist conjunctivitis was added to the symptoms. The rash did not appear till May and, and consisted of small round spots not bigger than the head of a pin, and generally discrete, though larger in some places where several had become confluent. The rash became steadily more intense, the eyelids were oedematous, and the boy suffered from a rather severe attack of measles. On May 4 th the rash was fading, the individual spots being still generally of small size, whilst in many instances small haemorrhages had appeared in them. Bronchitic signs were well marked, and the temperature finally settled on May $\mathbf{x}_{4}$ th.

CASE II.-A youth, G. W., aged . I5, was attacked with measles about the same time as the foregoing. In this case the first indication of on- set was a rise in temperature (100.4 $4^{\circ}$.) on the evening of April 24th. On April ${ }_{25}$ th there was congestion of the throat, with small spots of exudation on the tonsils, and slight rhinitis. For the next eight days the morning temperature was always above $100^{\circ} \mathrm{F}$., whilst the evening temperature was one, two, or more degrees higher. On April 26th there was coryza and conjunctivitis, on' April 27 th herpes of the lips, and on April 29 th the rash was flrst detected, consisting of some faint, blotchy erythemata on the face, and a few scattered macules on the body. The exanthem steadily became more marked though the individual macules remained of small size. On May 2 nd, as in the previous case, haemorrhages were noticed in the spots on the back. The attack was again a severe one, the pyrexia subsiding by lysis, and reaching the normal on May roth.

In both of these cases, then, the exanthem appeared on the sixth day from the onset of pyrexia, whilst in Case I the first indication of illness-that is, "croupy cough"-occurred on the ninth day preceding the eruption. It is thus evident that the stage of invasion in measles may be of very variable duration, and the question arises whether this variability takes place independently of or at the expense of the stage of incubation.

From a careful record of the epidemic in the Faroe Islands Panum $^{3}$ came to the conclusion that the "exanthem appears on the fourteenth day after the reception of the contagium." Like the cases which have been mentioned, he found that some patients suffered from coughs, pains in the eyes, or slight feverishness for six to eight days before the appearance of the exanthem, and that in a few mild cases the prodromal stage either was absent completely or lasted only one to two days. According to this rule, then, though either of the two periods taken separately may vary quite considerably, yet it is always at the expense of each other, their sum being practically a constant number.

Theoretically, one might expect that the absence or diminution of the prodromal stage would, as stated by Panum, occur in the mild cases ; and, conversely, one would expect to meet with early symptoms of disease (that is, a prolonged prodromal stage) in severer cases, the individuals being either predisposed, or the number of micro-organisms introduced at the time of infection being unusually virulent.

Unfortunately I am unable to specify the exact period of exposure in the two cases recorded, yet it seems to me that they tend to support the view I have mentioned, for, though both patients were strong and healthy, one finds that the attack in each case was very similar (thus, prolonged pyrexia, severe general symptoms, small size of individual macules late haemorrhage), and one can hardly help the conclusion that two such unusual attacks from the same source of infection probably owe their "abnormalities" to the virulent properties of the infecting organism.

1 Nothnagel's -Encyclopaedia, Art. Measles, p. $240 ; 2$ Münch. med. Woch., vol. $\dot{i}$, r903, p. $204 ;{ }^{3}$ Virchow's Archiv, r847, Band i, p. 497

\section{SOME REMARKS ON A CASE OF CHLOROMA*.}

\section{By PEVERELL S. HICHENS, M.A., M.D., Oxon. M.R.C.P.,} LoND.

Hon. Physician Northampton General Hospital.

I sHould perhaps offer some apology for spending, I will not say wasting, your time over a case so rare as one of chloroma. In the provinces our lives are severely practical, and we cannot as a rule afford ourselves the luxury of investigating the by-ways and hidden places of medicine.

A practitioner may be pardoned for knowing little or nothing about a case of an occurence so infrequent that he is almost sure never to meet one in the course of his lifetime.

But there are cases of such rarity, or supposed to be of such rarity, that they ought not to go unrecorded, and chloroma is one of them. Since the disease was first described by Allan Burns in $1823,{ }^{5} \mathrm{I}$ believe only 28 cases have been published, and hardly any of these have been diagnosed during life. The case that I am about to describe to you was unfortunately no exception to this rule. Though the patient did not live long enough to develop some of the most characteristic symptoms of this obscure disorder, yet I think I might have succeeded in arriving at a correct diagnosis if $I$ had known more of the literature concerning former cases.

I have ventured, therefore, to bring this case before you today with some general remarks on the disease of which it was

* Read before the South Midland Branch of the British Medical 
an example in the hope that, should another case of the same nature occur in our district, it may not arrive at the postmortem table undiagnosed.

The patient was a little boy aged 4 , who was sent up to me at the Northampton General Hospital by Dr. Grindon of Olney.

Family History.- His family history presented nothing of importance. He was one of seven children, of whom one died in infancy and his mother had had one miscarriage said to be from fright.

History.-As regards his previous history he had been quite healthy until he had an attack of mumps six months ago. From this he was considered to have completely recovered. According to his mother he received two months ago a blow on one temple, side unknown, but the child on being questioned about this pointed to the right iliac region. The child was apparently quite well until a fortnight before attending the hospital, when he woke one morning with paralysis of the left side of the face. During the fortnight he complained a good deal of pain in the head and in both mastoid regions, and was sent up to me by Dr. Grindon under the impression that he probably had some form of intracranial disease.

Condition.-On examination, he was a well-nourished child with a good colour. He presented complete paralysis of the left side of the face, including the forehead muscles. There was no paralysis of the ocular muscles or squint, and no signs of optic neuritis. There was no history of discharge from the ears, but the tympanic membranes could not be seen owing to wax in the external auditory canals. The only other abnormality noticed besides the left facial paralysis was a slight puffy swelling over the right temporal bone just above and outside the right orbital cavity.

Diagnosis.-Owing to the absence of optic neuritis and other symptoms of intracranial tumour, together with the fact that the muscles of the forehead were paralysed as well as those of the face, it seemed to me more probable that the paralysis was of peripheral origin, and possibly of a rheumatic nature, so the child was given $2 \mathrm{gr}$. of potassium iodide three times a day and sent home.

After-history.-In eleven days he returned evidently worse, with a history of having been sick several times in the interval, of having been crying with pain in the right ear, and of having had several rises of temperature. His temperature was now $99.2^{\circ}$, and he looked dull and ill. The ears were syringed and examined. There was some inflammation of the right external auditory meatus, but the membranes on both sides appeared healthy. There was tenderness on percussing over the right mastoid process. The fundi of the eyes were again examined, and the left disc appeared a little blurred, but there were no definite signs of optic neuritis. The facial paralysis remained as before, and involved a before the left side of the face and forehead. The swelling in the right temporal region appeared to have somewhat increased in size, and a small, exactly symmetrical swelling had now made its appearance in the left temporal region. There was a question whether the left eye was a little more prominent than the right, but we came to the conclusion that this very slight appearance of extra prominence was due to inability to close the left eyelid. No abnormal physical signs were observed in the chest or abdomen. The urine was acid, specific gravity 1020, and contained no albumen or sugar.

History in Hospital.-The child was admitted to the hospital on that day, July I 5 th, and the after-history of his case until his death on July 27 th may be briefly stated. The right mastoid region was leeched and hot fomentations were applied, which in a great measure relieved his pain, but he became increasingly drowsy and weak. Potassium iodide and perchloride of mercury were also given on the off-chance that there might be some syphilitic element in the case. Very few developments took place before death. The temporal swellings somewhat increased, and on the afternoon of the $26 \mathrm{th}$ some petechial spots were noticed in the skin of the abdomen and flank, and a small subcutaneous haemorrhage close to the inner canthus of the right eye. On July 27 th, at 6.30 a.m., the patient began to bleed profusely from the nose and also vomited blood, which had probably been swallowed. He died at 9 a.m. His temperature during his time in the hospital wa nearly always at $99^{\circ}$ or below, but on the $24^{\text {th }}$ of July it rose to $102^{\circ}$ and before death reached 102. $6^{\circ}$ I. should mention that $\mathrm{my}$ surgical colleague, Dr. Milligan, saw the case with me and we came to the conclusion that it was probably one of sarcoma with metastasis, but we both agreed that we had never seen a case like it.

Necropsy. - The body is that of a well-nourished child. There are a few petechial spots scattered about the thorax and abdomen and there is a small subcutaneous haemorrhage just above the inner canthus of the right eye. In the temporal regions just above and outside either orbital cavity are two symmetrical swellings. They are rather hard to the touch. There are no signs of inflammation over them and the skin is not involved. Thorax, larynx, trachea, bronchi, lungs and pleurae healthy. No enlargement of bronchial glands. Thymus: Not seen. Heart: Weight $4 \mathrm{oz}$., healthy. Some dotted haemorrhage in the pericardium. Abdomen : Liver, weight $24 \mathrm{oz}$., somewhat congested. Scattered about the liver are small masses of whitish' green new growth; in some places the growth is conglomerated into roundish masses, in others it grows in a ramifying manner along the portal spaces. There is no appearance of a capsule round the growths. Kidneys: Weight, $4 \frac{1}{2}$ ozs. Scattered about both cortices are numerous very small masses of whitish-green new growth. On the right kidney there are also some small haemorrhages into the cortex under the capsule. Spleen: Weight, $3 \mathrm{oz}$. congested, but otherwise healthy. Stomach and intestines: Healthy. Just above the pancreas at the back of the small omentum is a mass of new growth, of a greyish green colour, very much the colour of turtle fat. The mesenteric glands are enlarged and there are haemorrhages into them; but they do not present the green appearance.
Head: On removing the skin from the calvarium the swellings external to the orbits are found to be under the temporal muscles. On incising the swellings they are found to be produced by the same green new growth, which here apparently starts from the pericranium, and is pushing forward and infiltrating the deeper surface of the temporal muscles. There was no appearance of the growth invading or eroding the underying bone. The orbital cavities contained small masses of the green growth above the eyes in the orbital fat. These masses had not reached such a size that they projected under the conjunctiva or caused proptosis. On removing the calvarium the dura mater presented a striking appearance. The green growth was found to be scattered diffusely over the outer surface of the dura mater all along and for some distance on both sides of the superior longitudinal sinus. The masses of growth were in no cases dense. They did not invade the underlying brain, but they pitted and slightly eroded the overlying calvarium. On removing the brain there was found to be very much larger masses of growtl of the same character in the dura mater in the basal fossae. These were scattered numerously here and there, and were especially noticeable about the petrous portion of the right temporal bone. They did not appear to invade the bone or the brain anywhere. There was a large excess of cerebro-spinal fluid in the leptomeninges. The brain itself was healthy, and contained no masses of growth, and the nerves coming off from the brain appeared quite normal. As a special request was made that there should be no disfigurement, none of the bones were examined except the petrous portions of the temporal bones, and the ribs where they were cut across to open the thorax. There appeared to be no green infiltration in these situations.

Microscopical Examination.-Portions of the growth from the dura mater, the temporal muscle, the liver, kidney, and the mass above the pancreas were hardened in alcohol and embedded in paraffin, and the sections of them are before you to-day, The growth is an infiltrating one. The neighbouring tissues show no signs of counter irritation. There is no attempt at the formation of a fibrous capsule. The infiltrating character is specially well shown in the seetions of the temporal muscle and kidneys. In these the remains of muscle flbres, glomeruli, and tubules may be seen scattered about in the midst of the new cell formation. In the liver this is not so noticeable. The liver cells end sharply, and the new formation begins sharply, but there is no attempt at the laying down of a limiting membrane between the two. The new formation itself consists almost entirely of rather small round or oval cells; on the whole, most of them are, I think, smaller than a lymphogiant cells to be seen. There is very little stroma noticeable anywhere. In some places the cells seem to be embedded in an amorphous material of a clear, transparent character ; in others a very delicate stroma may be seen branching about amongst the cells. This is best marked in the sections from the green mass above the pancreas. The appearance is the intracellular hyaline granules are seen which Melville. Dunlop speaks of.

The post-mortem appearances show that the case was a typical example of chloroma, dying suddenly at a somewhat early visible. This was very regrettable, as the absence of a diagnosis caused a serious omission in the examination of the case which cannot now be rectified. No examination was made of the blood.

Now it has been shown by many observers that very marked changes occur in the blood in chloroma, changes which are apparently closely analogous to or identical with those which occur in lymphatic leukaemia.

There is a great increase of lymphocytes, and at the same time a great diminution in the number of the red corpuscles. In Rosenblath and Risel's second case, for example, the blood count showed 3,700,000 red corpuscles and 40,000 white corpuscles per c.mm. ${ }^{23}{ }_{24}$ In Melville Dunlop's case the blood count showed thaemoglobin 32 per cent., red corpuscles I,800,000, white corpuscles 245,000 per c.mm.

Melville Dunlop's case was in other respects so like the present one under discussion that it may be of interest to give a brief epitome of it.

His patient was'a boy aged 5 . For fully a year patches of ecchymosis had been noticed from time to time under the skin, and for five months extreme pallor. Two months before admission he became dull and languid, his eyes became prominent, and he gradually got deaf. : On admission his blood condition was as above recorded, There were numerous petechial haemorrhages in the skin. There was some prominence of the eyes, with anaemta and oedema of the conjunctivae. There were a few slightly enlarged glands below the lower jaw on both sides in the posterior triangle of the neek and in both groins. The axillary glands were not enlarged. The thyroid and thymus were normal. The respiratory and haemic systems were normal with the exception of haemic bruits in the vessels on both sides of the neck. The digestive system was normal. After a short time purplish swellings developed on the hard palate and on the lower jaw external to the teeth on the right side. Later, symmetrical rounded swellings appeared in the temporal region. A few days later the eyelids began to be infiltrated, and then greenish-yellow tumours of jelly-lize consistency appeared at the inner canthi, and gradually advanced over the canthi. The retinal veins were distended and tortuous; ${ }^{+-}$tind the appearance of the discs suggestive of commencing optic neuritis. 
Later examination of the blood showed haemoglobin $x 2$ per cent., leuocytes 107,000 , and red corpuscles $81_{5}, 000$ per c.mm. At the necropsy the ribs, manubrium sterni, and numerous other bones showed green material in the medulla. The periosteum of the vertebrae, from the neck to the pelvis, was infiltrated with the same green material, as. was also the dura mater, the pericranium beneath the temporal muscle, the orbital cavities, the kidneys, the pancreas, and the glands just above the pancreas, the soft palate, tonsil, pharynx, mouth, and gums. The brain and spinal cord were healthy. Microscopically, the tumours consisted of large, round or oval-shaped cells, slightly larger than a white blood corpuscle, and containing often more than one nucleus, and occasionally a nucleolus. These cells were either embedded in an intercellular amorphous material of a very clear and transparent character or in a delicate network. At other times the tumour was interspersed with coarse bundles of connective tissue. In the midst of this granules with highly refractile properties were found lying in and between the cells.

I think it will be seen from this account that, with the exception of the involvement of the liver, this case very closely resembled my own, and would probably have still more closely resembled it had the life of my case been sufficiently prolonged.

A summary of the characteristics of the disease chloroma has been given by Hüber, ${ }^{15}$ by Dock, ${ }^{\circ}$ and by Byrom Bramwell. ${ }^{6}$ Hüber based his remarks on seven cases. His oldest patient was 24 , and he found that males were more often affected than females.

There were usually general symptoms such as dullness, apathy, pallor, and palpitation of the heart. There was often exophthalmos with violent pains and frequently deafness. There was frequently epistaxis and difficulty of breathing from tumours in the nasal cavity. The brain and nerves were not often affected. Headache and giddiness, apathy and somnolence, were common. Purpura and haemorrhages were frequent, and the blood condition above described was characteristic. Körner describes tinnitus and deafness in ten cases, ${ }^{18}$ and Behring has seen apoplectiform seizures. ${ }^{4}$ In Waldstein's case the urine was yellowish green. ${ }^{27}$ Dock, who published his paper in 1893, based his analysis on 17 cases. His results in the main agree with Huber's. The average age in 15 cases was 15.26 years. In Waldstein's case the age was 44. The average duration of the illness in 12 cases was 5 months. The early symptoms were pallor in 6 cases, emaciation 3, nose bleed 3, scorbutus 1 , petechiae 1 , loss of energy 2, fever I, frequent pulse 3 , headache 3 , tinnitus aurium 2 , deafness 7 double vision 1 , loss of vision 2 , exophthalmos 6, facial paralysis 2, feeling of oppression 1 , prominence of temples, tumour of mammary region, feeling of constriction, toothache, 1 each.

The symptoms occurring later on were thirst, fatigue strabismus, double vision (in addition to those mentioned above), deafness, otorrhea, pain in epigastrium, dyspnoea, abscesses, anaemia, oedema, haemorrhages from the lunge, intestines, in the skin and from the nose; obstruction of the nose, fever, frequent pulse, nephritis, irritability, coma, delirium, convulsions, wasting, constipation, vomiting, involuntary stools, diarrhoea, anorexia, pain in the region of the liver, craving for meat (King and Dock), disgust for meat (Aran), enlargement of spleen (2, probably 4 cases), swelling of thyroid. Death occurred from profound exhaustion, inability to take food, and often with some of the nervous symptoms mentioned above.

It will be seen from Dock's account that he has put down all the symptoms that occurred in all the cases. Many of them are of course in no sense characteristic of the disease and are, indeed, often mutually contradictory. Byrom Bramwell's summars, which is more recent, is perhaps more helpful in enabling us to attain a clear idea of the characteristics of the disease. He finds that in typical cases the characteristic features are as follows:-

r. The presence of lymphoid deposits in the orbits, temporal fossae, and periosteum of the bones of the skull, and the symptoms and signs arising therefrom.

2. The green colour of the lesions.

3. A profound blood change, of which the characteristic feature seems to be an enormous excess of lymphocytes.

4: The bone marrow, spleen, lymphatic glands, and organs throughout the body are affected (infiltrated with lymphoid deposits) as in lymphatic leukaemia.

Finally, may I be allowed a last word about the nature of the disease? Virchow regarded it as a kind of sarcoma. Byrom Bramwell seems to regard it as possibly identical with lymphatic leukaemia : I suppose a lymphatic leukaemia with local deposits. Dock does not seem to regard it as a sarcoma because of the absence of polynuclear giant cells.

On the other hand, the erosion of the bones which occurs in some cases, and which was present in the calvarium of my case, is certainly suggestive of sarcoma.

May it not be possible that both views are right? That lymphatic leukaemia is, as it were, a fluid sarcoma of the haemopoietic system, and that chloroma is only another manifestation of the same disease characterized by solid deposits.

1 s. Ayres, Journ. Amer. Med. A880c.. Chicago, 1896, xxvii, 986-988. 2 Aran, Arch. Gen. de Med., r854, T. ii, P. 385 . 3 Balfour, Edin, Med. and Surg, Journ., 1835, xliii, p. 319. 4 Behring and Wicheskiewicz, Berl. klin. Woch., 1882, S. 509. ${ }^{5}$ A. Burns, Observ. on the Surg. Anat. of the Head and Neck, $18 \mathrm{st}$ Amer. Edit., Baltimore, 1823, p. 386. 6 Byrom Bramwell, Lancet, r9o2, vol. i, p. 520 Scottish Med. and Surg. Journ., ${ }^{1902,}$ vol. x, p. 219 . ${ }^{7} \mathrm{H}$. Chiari, Zeit. n. 8., C.'vi, 152-185. 9, Dres77, T. V. ${ }^{8}$ Dock, Amer. Journ. Med. Soc., 1893, Dunlop, Lancet, rooz, vol. i, p. 45. 11 Durand-Fardel, Journ. Heb. d. Prog. d.

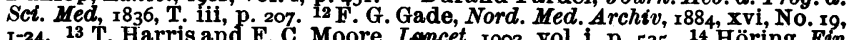
1-24. 13 T. Harris and F. C. Moore, Lancet, 1902, vol. i, p. 525 . 14, Höring, Ein Inst. zu Tibingen Chloroms., Brunswick, r89r; Arb. a. d. Geb. d. Path. Anat. Bd. xix, S. 128, Leipzig. $16 \mathrm{R}$. Hutehison, Med. Annual, 1903, p. 187. i7 King, Month. Journ. Med. Sc., 1853, vol. Xvii, p. 97-104. 18 Körner, Arch. Otol., New York ${ }_{1897}$, vol. xxvi, p. ${ }^{289-93 .} 19 \mathrm{G}$. Lang, Arch. Gén. d. Méd., Paris, 1893,

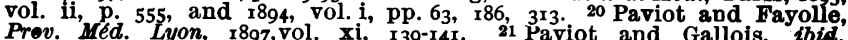
1896, vol. x, 570 ; Compt. Rend. Soc. de Biol., Paris Gallois, vol. $x$, S. 3, 919-2x; Lyon Méd., 1896, C. Xxxiii, 488-90, I; Mem. et Compt. Recklinghausen, Tagebl. de Yyon, ${ }^{1897, ~ C . ~ X x x v i i, ~ p t . ~} 2$, 176-8. 1885. L. viii, 421, 2s W. Risel, Deut. Arch. f. klin. Med., roor, Bd. lx xii, p. 3x. and Surg. Journ., 19o2, vol. ii, p. r37, p. I. ${ }^{25} \mathrm{~L}$. R. Sutherland, Scot. Med, p. 183; ibid, 1903, vol. ii, p. 530 . 27 Waldstein, Virchow's Archiv, 1883. Bd. xci, S. 12

\section{ON THE RELATION OF THE ARGYLL-ROBERTSON PHENOMENON TO SYPHILIS.*}

BY J. MICHELL CLARKE, M.A., M.D.CANTAB., F.R.C.P., Professor of Pathology, University College, Bristol ; Physician to Brist o General Hospital.

THE object of the present paper is to offer some observations on the relation of the Argyll-Robertson phenomenon to past syphilitic infection. It is hardly necessary to allude to the importance of this sign as a frequent and often early symptom of certain degenerative diseases of the central nervous system.

With regard to the general incidence of the symptom, it is now usually stated that it occurs in tabes dorsalis, general paralysis, and acquired or congenital syphilis, and that it is only exceptionally found in other diseases of the nervous system. Thus Dr. Mott" says that "practically speaking reflex rigidity of the pupils to light and pain exists only in tabes, general paralysis, and acquired or congenital syphilis:" he adds that very rarely cases of focal cerebral lesions, especially of the corpora quadrigemina, may show ArgyllRobertson pupils, and that "some authors point out that in alcoholism and other diseases reflex rigidity of the pupil may exist, but these are cases complicated by syphilis."

Dr. James Taylor ${ }^{2}$ writes to the same effect, and says that "its frequent association with diseased conditions of the nervous system, usually regarded as syphilitic or parasyphilitic, and its occurrence as an isolated phenomenon in patients with a syphilitic !history makes it possible that this disease has a close causal connexion with it.

Sir William Gowers, ${ }^{3}$ after remarking that it is chiefly seen in tabes and general paralysis, and occasionally in other degenerative diseases of less definite type, states that when he had found it existing alone, in most of the cases there had been constitutional syphilis many years before.

Drs. R. Cestan and Dupuy-Dutemps, ${ }^{4}$ in a paper on the Argyll-Robertson phenomenon, based on the examination of a large number of cases, state that, apart from tabes and general paralysis, it is altogether exceptional to find this sign either occurring as an isolated symptom or associated with other mental or organic nerve disease, and they conclude that its presence points to congenital or acquired syphilis, with a possible exception for some cases of syringomyelia and of the interstitial hypertrophic neuritis of Dejerine.

We should expect, therefore, to find, according to authors, reflex pupil rigidity most frequently, apart from tabes and general paralysis, in cases of former syphilitic infection.

Tabes and general paralysis are now very generally regarded as, in most cases, the remote consequence of a past attack of syphilis, as parasyphilitic affections. In a small number of cases. hnwever. no history or evidence of syphilis 